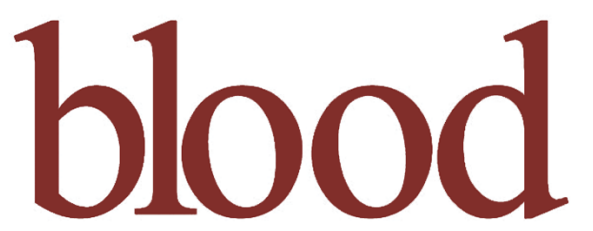

2002 100: 2393-2398

Prepublished online May 31, 2002;

doi:10.1182/blood-2002-02-0420

Studies of FLT3 mutations in paired presentation and relapse samples from patients with acute myeloid leukemia: implications for the role of FLT3 mutations in leukemogenesis, minimal residual disease detection, and possible therapy with FLT3 inhibitors

Panagiotis D. Kottaridis, Rosemary E. Gale, Stephen E. Langabeer, Marion E. Frew, David T. Bowen and David C. Linch

Updated information and services can be found at:

http://bloodjournal.hematologylibrary.org/cgi/content/full/100/7/2393

Articles on similar topics may be found in the following Blood collections:

Clinical Trials and Observations (2413 articles)

Neoplasia (4100 articles)

Information about reproducing this article in parts or in its entirety may be found online at:

http://bloodjournal.hematologylibrary.org/misc/rights.dtl\#repub_requests

Information about ordering reprints may be found online at:

http://bloodjournal.hematologylibrary.org/misc/rights.dtl\#reprints

Information about subscriptions and ASH membership may be found online at:

http://bloodjournal.hematologylibrary.org/subscriptions/index.dtl

Blood (print ISSN 0006-4971, online ISSN 1528-0020), is published semimonthly by the American Society of Hematology, 1900 M St, NW, Suite 200, Washington DC 20036.

Copyright 2007 by The American Society of Hematology; all rights reserved.

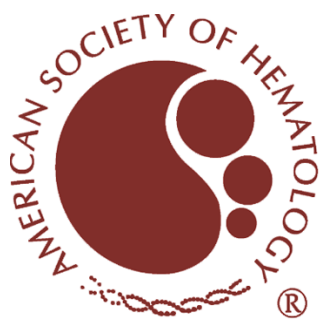




\section{Studies of FLT3 mutations in paired presentation and relapse samples from patients with acute myeloid leukemia: implications for the role of FLT3 mutations in leukemogenesis, minimal residual disease detection, and possible therapy with FLT3 inhibitors}

Panagiotis D. Kottaridis, Rosemary E. Gale, Stephen E. Langabeer, Marion E. Frew, David T. Bowen, and David C. Linch

FLT3 mutations, either internal tandem duplications (ITDs) or aspartate residue 835 (D835) point mutations, are present in approximately one third of patients with acute myeloid leukemia (AML) and have been associated with an increased relapse rate. We have studied FLT3 mutations in paired presentation and relapse samples to ascertain the biology of these mutations and to evaluate whether they can be used as markers of minimal residual disease. At diagnosis, 24 patients were wild-type $F L T 3$, and 4 acquired a FLT3 mutation at relapse $\left(2{\mathrm{D} 835^{+}, 2}^{+}\right.$ $\mathrm{ITD}^{+}$), with a further patient acquiring an ITD at second relapse. Of 20 patients \left. positive at diagnosis (18 ITD,$+ 2{\mathrm{D} 835^{+}}^{+}\right), 5$ who were all originally ITD ${ }^{+}$had no detectable mutation at relapse, as determined by a sensitive radioactive polymerase chain reaction. One of these patients had acquired an $\mathrm{N}$-Ras mutation not detectable at presentation. Furthermore, another patient had a completely different
ITD at relapse, which could not be detected in the presentation sample. These results indicate that FLT3 mutations are secondary events in leukemogenesis, are unstable, and thus should be used cautiously for the detection of minimal residual disease. (Blood. 2002;100: 2393-2398)

(C) 2002 by The American Society of Hematology

\section{Introduction}

Approximately $80 \%$ of patients with acute myeloid leukemia (AML) younger than 55 years of age achieve complete remission (CR) following intensive induction therapy. ${ }^{1}$ However, the actuarial survival at 5 years is only just over $40 \%$ because most patients relapse and die of their disease. ${ }^{1}$ Considerable effort has therefore been directed at identifying molecular markers that can be used to detect residual disease or predict relapse at an earlier stage and lead to therapeutic intervention before overt hematological relapse occurs.

Ideally, a candidate marker for minimal residual disease (MRD) should always or frequently be present in a specific disease and it should be easy to assay and stable; that is, always present at relapse. In lymphoid malignancies, clonal rearrangements of either immunoglobulin or T-cell receptor genes are suitable for such analysis. ${ }^{2}$ They occur in up to $90 \%$ of patients, can be detected using sensitive polymerase chain reaction (PCR) techniques, and reappear at relapse, although development of secondary rearrangements has been noted in some cases. ${ }^{3}$ Studies evaluating their usefulness in clinical practice as a predictor of relapse have shown that the presence and level of residual leukemia can correlate with the risk of early relapse in acute lymphoid leukemia. ${ }^{4}$ Similarly, the $\mathrm{BCR} / \mathrm{ABL}$ fusion transcript is present in nearly all patients with chronic myeloid leukemia (CML), and a number of different approaches have been used to correlate this marker with disease status and outcome. ${ }^{5-8}$

In AML, the use of MRD has been limited by the lack of suitable specific molecular markers and the diversity of those that do exist. Although cytogenetic markers have proved to be significant prognostic indicators, fewer than $50 \%$ of patients have an identifiable cytogenetic abnormality. ${ }^{1}$ Some patients have partial or complete loss or gain of a chromosome, but such abnormalities can be identified only using relatively insensitive "whole cell" techniques, and even the more sensitive fluorescence in situ hybridization technique requires evaluation of thousands of cells. ${ }^{9}$ There are 3 molecular markers that have been used for MRD studies: $P M L / R A R \alpha$ fusion transcript arising from the $\mathrm{t}(15 ; 17)$ translocation, AML1/ETO arising from $\mathrm{t}(8 ; 21)$, and $C B F B / M Y H 11$ from inv(16). ${ }^{10-13}$ Quantitative assays are necessary, particularly because several groups have shown that patients who are positive for AML1/ETO using sensitive reverse transcription (RT)-PCR assays can remain in morphologic and clinical remission for many years. ${ }^{14,15}$ Nevertheless, reappearance of the marker, or persistence at a certain level after induction chemotherapy, does generally signify an increased risk of relapse. ${ }^{16,17}$

However, these 3 markers together account for only approximately one fourth of adult AML patients, ${ }^{1}$ and other markers are required to extend the potential application of MRD to more AML patients. Recent studies have demonstrated that mutations in the FLT3 gene occur in about one third of adult AML patients. In $22 \%$ to $27 \%$ of patients, there is an internal tandem duplication (ITD) in the juxtamembrane region between exons 14 and $15^{18,19}$ (previously called exons 11 and 12). ${ }^{20}$ The extra sequence varies between 18 base pairs (bp) and $222 \mathrm{bp}$ (as detected in one patient in the
From the Department of Haematology, University College London, London, United Kingdom; and the Department of Molecular and Cellular Pathology, Ninewells Hospital, Dundee, United Kingdom.

Submitted February 8, 2002; accepted May 1, 2002. Prepublished online as Blood First Edition Paper, May 31, 2002; DOI 10.1182/blood-2002-02-0420.

P.D.K. and M.E.F. are supported by the Leukaemia Research Fund.
Reprints: Panagiotis D. Kottaridis, Department of Haematology, University College London, 98 Chenies Mews, London WC1E 6HX, United Kingdom; e-mail: p.kottaridis@ucl.ac.uk.

The publication costs of this article were defrayed in part by page charge payment. Therefore, and solely to indicate this fact, this article is hereby marked "advertisement" in accordance with 18 U.S.C. section 1734.

(C) 2002 by The American Society of Hematology 
present study), but the resulting protein sequence remains in frame and is thought to lead to a constitutively activated tyrosine kinase receptor. ${ }^{21-23}$ Multivariate analysis has shown that presence of the mutation is the most significant factor predicting for relapse, and it can add additional prognostic information to a cytogenetic risk group. ${ }^{19}$ A further $7 \%$ of patients have a mutation of aspartate residue 835 (D835) in the activation loop of the second kinase domain, predominantly to tyrosine or valine, but occasionally to other amino acids. ${ }^{24,25}$ This also leads to an activated receptor, although the clinical significance is unclear at present due to the small number of patients studied.

To gain further insight into the role of FLT3 mutations in AML and to determine whether they are suitable markers for MRD, we have therefore studied paired samples from patients at presentation and relapse for the presence of ITDs and D835 alterations.

\section{Patients, materials, and methods}

\section{Patients}

Paired peripheral blood or bone marrow samples at presentation and first relapse were available from 44 patients with de novo AML who were treated with protocols from the United Kingdom Medical Research council (MRC) AML 10 and 12 trials. ${ }^{1,19}$ A further sample at second relapse was obtained from one patient. Of these patients, 11 had AML French-American-British type M1; 7, M2; 5, M3; 13, M4; 7, M5; and 1 patient had RAEB-t. Median age at presentation was 42 years (range, $12-61$ years), and median white cell count was $50.1 \times 10^{9} / \mathrm{L}$ (range, $0.8-541 \times 10^{9} / \mathrm{L}$ ). DNA samples were used for analysis in 42 patients; in the remaining 2 patients, only RNA samples were available. Paired DNA samples from patients at presentation and first complete remission (CR) following induction chemotherapy were also studied in $13 \mathrm{AML}$ patients who had a mutation in the FLT3 gene at diagnosis. CR was defined as a normocellular bone marrow containing fewer than $5 \%$ blast cells. Results of FLT3/ITD analysis at diagnosis have already been reported on some of the patients used in these studies. ${ }^{19}$

\section{Detection of mutations in the $F L T 3$ gene}

ITDs For FLT3/ITDs, genomic DNA was amplified as previously described to produce a fragment of $328 \mathrm{bp}$ from wild-type (WT) alleles, which included exons 14 and 15 and the intervening intron. ${ }^{19}$ The same primers were used to analyze cDNA, but the fragment produced was $90 \mathrm{bps}$ smaller. Semiquantitative PCR using a ${ }^{32} \mathrm{P}$-labeled PCR primer was also carried out as previously described. ${ }^{19}$ To evaluate sensitivity of the technique, WT cells were mixed with cells from a patient carrying predominantly mutant alleles to create 9 different mixtures containing between $100 \%$ and $0.01 \%$ patient cells. DNA was extracted and assayed radioactively. Reproducibility was assessed by 5 separate analyses of 3 patient samples with high, intermediate, or low level of mutant FLT3.

D835 Mutations at residue D835 in exon 20 (previously exon 17) were detected as described by Yamamoto et al. ${ }^{24}$ Approximately $100 \mathrm{ng}$ DNA was added to a reaction mix containing $1 \times$ buffer $\left(16 \mathrm{mM}\left(\mathrm{NH}_{4}\right)_{2} \mathrm{SO}_{4}, 67\right.$ $\mathrm{mM}$ Tris $\mathrm{HCl} \mathrm{pH}$ 8.8, 0.01\% Tween 20), $1.0 \mathrm{mM} \mathrm{MgCl}_{2}, 200 \mu \mathrm{M}$ dNTPs, and 10 pmols each primer (Table 1) in a total volume of $19 \mu \mathrm{L}$. The mixture was heated to $95^{\circ} \mathrm{C}$ for 5 minutes and held at $85^{\circ} \mathrm{C}$ while $1 \mu \mathrm{L}$ containing 0.5U BIOTAQ DNA polymerase (Bioline, London, United Kingdom) was added; then 35 cycles each of $95^{\circ} \mathrm{C}$ for 30 seconds, $63^{\circ} \mathrm{C}$ for 30 seconds, and $72^{\circ} \mathrm{C}$ for 30 seconds were performed, followed by 5 minutes at $72^{\circ} \mathrm{C}$. Amplified products were digested with EcoRV then electrophoresed through $4 \%$ agarose gels and visualized under ultraviolet light with ethidium bromide staining. In alleles containing a D835 mutation, the 114-bp PCR fragment remained uncut, but in WT alleles it was digested to fragments of 68 and 46 bps.

\begin{tabular}{|c|c|c|}
\hline Oligonucleotide primer & Primer & Sequence \\
\hline FLT3/ITD & $\mathrm{F}$ & 5'-GCAATTTAGGTATGAAAGCCAGC-3' \\
\hline FLT3/ITD & $\mathrm{R}$ & $5^{\prime}$-CTtTCAGCATTTtGACGGCAACC-3' \\
\hline FLT3/D835 & $\mathrm{F}$ & $5^{\prime}-\mathrm{CCGCCAGGAACGTGCTTG}-3^{\prime}$ \\
\hline FLT3/D835 & $\mathrm{R}$ & $5^{\prime}-$ GCAGCCTCACATTGCCCC-3' \\
\hline \multirow[t]{2}{*}{ N-RAS exon 1 (DNA) } & $\mathrm{F}$ & $5^{\prime}-$ GACTGAGTACAAACTGGTGG-3' \\
\hline & $\mathrm{R}$ & $5^{\prime}-$ TGCATAACTGAATGTATACCC-3' \\
\hline \multirow[t]{2}{*}{ N-RAS exon 2 (DNA) } & $\mathrm{F}$ & $5^{\prime}$-CAAGTGGTTATAGATGGTGAAACC-3' \\
\hline & $\mathrm{R}$ & $5^{\prime}$-AAGATCATCCTTTCAGAGAAAATAAT-3' \\
\hline \multirow[t]{2}{*}{ N-RAS exons $1+2$ (cDNA) } & $\mathrm{F}$ & $5^{\prime}-\mathrm{CTGTCCAAAGCAGAGGCAGTG-3^{ \prime }}$ \\
\hline & $\mathrm{R}$ & 5'-AGGCTTCCTCTGTGTATTTGCC-3' \\
\hline \multirow[t]{2}{*}{ KB9 } & $\mathrm{F}$ & $5^{\prime}-$ TGCAAAGGCTTGGAGGGCTGATG-3' \\
\hline & $\mathrm{R}$ & $5^{\prime}-$ ATCTCGGACAACAGCAGGCCTCG-3' \\
\hline \multirow[t]{2}{*}{ D21S270 } & $\mathrm{F}$ & 5'-GAAATGTTTTAATAAATGGTGGTTA-3' \\
\hline & $\mathrm{R}$ & 5'-ACAAAGTTATGGTCAAGGGG-3' \\
\hline \multirow[t]{2}{*}{ D21S65 } & $\mathrm{F}$ & $5^{\prime}-$ CCGAAAACTTACTGGAGAAC-3' \\
\hline & $\mathrm{R}$ & $5^{\prime}$-GATCATCCAGGAATCACCAA-3' \\
\hline
\end{tabular}

\section{Polymorphic marker analysis}

In cases where differences were observed between the results at presentation and relapse, 3 polymorphic markers were used to confirm that the DNA samples were from the same patient: KB9 on chromosome 19, and D21S270 and D21S65 on chromosome 21. ${ }^{26,27}$ One primer from each pair (Table 1) was ${ }^{32} \mathrm{P}$ end-labeled, and PCR was performed as described above except that only 25 cycles of amplification were used and the annealing temperatures were $58^{\circ} \mathrm{C}$ for D21S270 and D21S65, and $65^{\circ} \mathrm{C}$ for KB9. Products were electrophoresed through denaturing polyacrylamide gels (7M urea, $6 \%$ polyacrylamide crosslinker ratio $37.5: 1,0.5 \times$ Tris-BorateEDTA [ethylenediaminetetraacetic acid]), the gels were dried and exposed to Hyperfilm (Amersham, Little Chalfont, United Kingdom).

\section{Cloning and sequencing of PCR products}

PCR products from $\mathrm{ITD}^{+}$patients either were sequenced directly or were cloned into the pGEM-T vector (Promega, Madison, WI) and selected clones sequenced using an Applied Biosystem 310 Analyzer with BigDye version 2 terminator chemistry (Applied Biosystems, Foster City, CA).

\section{Detection of N-Ras gene mutations}

Samples were screened for mutations in codons 12,13, and 61 of the $N$-Ras gene using heteroduplex analysis (WAVE technology; Transgenomic, San Jose, CA). For DNA samples, a 241-bp fragment was amplified for exon 1 containing codons 12 and 13, and a 201-bp fragment for exon 2 containing codon 61. Thirty-five cycles of amplification were performed on approximately 100-ng genomic DNA using 0.625 units HotStarTaq (Qiagen, Crawley, West Sussex, United Kingdom) per $25 \mu \mathrm{L}$ reaction, $1 \times$ manufacturer's buffer, $200 \mu \mathrm{M}$ dNTPs, and 12.5 pmol each primer (Table 1). After an initial denaturing cycle of 15 minutes at $95^{\circ} \mathrm{C}$, each cycle was 30 seconds at $94^{\circ} \mathrm{C}, 60$ seconds at $55.5^{\circ} \mathrm{C}$, one minute at $72^{\circ} \mathrm{C}$, followed by 10 minutes at $72^{\circ} \mathrm{C}$. PCR products were denatured at $95^{\circ} \mathrm{C}$ for 5 minutes then cooled slowly to $25^{\circ} \mathrm{C}$ to allow heteroduplexes to form and be analyzed by denaturing high performance liquid chromatography (dHPLC). For cDNA a single fragment of 296 bp was amplified, which covered exons 1 and 2 , and the annealing temperature was $64^{\circ} \mathrm{C}$. The sensitivity of the dHPLC is such that at least $10 \%$ mutant DNA can be confidently detected in a sample (manuscript in preparation). Samples exhibiting an abnormal dHPLC profile were sequenced as above.

\section{Results}

\section{Evaluation of semiquantitative PCR analysis}

Sensitivity of the method was determined from analysis of mixtures of WT cells and cells from a patient with 94\% FLT3/ITD 
alleles. The mutant could be detected when $\geq 0.5 \%$ of total FLT3. Quantification of the different mixtures gave results that were in good agreement with the expected values: expected and observed values were $47 \%$ and $48 \% ; 19 \%$ and $23 \% ; 9.4 \%$ and $12.8 \% ; 4.7 \%$ and $5 \% ; 1 \%$ and $1.4 \%$, respectively. The results were highly reproducible: 5 analyses of 3 samples with different FLT3/ITD levels gave mean $\pm \mathrm{SD}$ values of $94.4 \% \pm 0.5 \%$ (range, $93 \%-95 \%), 53.5 \% \pm 1.1 \%(52 \%-55 \%)$, and $12.8 \% \pm 0.8 \%$ (12\%-14\%), respectively.

\section{Paired presentation/remission samples}

Remission samples from 13 patients who had a FLT3 mutation at presentation were studied. All 13 patients had an ITD, median mutant level $44 \%$ of total FLT3 (range, 2\%-90\%), and 1 patient also had a D835 mutation (D835Y). In remission all patients lost their mutation(s), confirming that FLT3 mutations are leukemia-specific.

\section{Paired presentation/relapse samples}

Patients without a FLT3 mutation at presentation. Of the 24 patients studied who had only WT FLT3 alleles at presentation, 20 patients remained WT at first relapse and 4 patients had acquired a FLT3 mutation (Table 2). Two patients acquired a D835 mutation, both $\mathrm{G}>\mathrm{T}$ leading to substitution of tyrosine for aspartate, and 2 patients gained a FLT3/ITD. The D835 mutants accounted for approximately half of the total FLT3 in the samples, and in the

Table 2. FLT3 status and relative percentage of mutant in PB or bone marrow from 44 AML patients at presentation and relapse

\begin{tabular}{|c|c|c|c|c|c|c|c|c|}
\hline \multirow[b]{2}{*}{ No. } & \multicolumn{4}{|c|}{ Presentation } & \multicolumn{4}{|c|}{ Relapse } \\
\hline & FLT3 & $\%$ Mutant & Sample & $\%$ Blasts & FLT3 & $\%$ Mutant & Sample & $\%$ Blasts \\
\hline 1 & WT & - & PB MNC & 90 & WT & - & NA & 76 \\
\hline 2 & WT & - & BM & 97 & WT & - & PB MNC & NA \\
\hline 3 & WT & - & PB MNC & 95 & WT & - & BM & NA \\
\hline 4 & WT & - & PB MNC & 28 & WT & - & BM & 42 \\
\hline 5 & WT & - & NA & 100 & WT & - & BM & 95 \\
\hline 6 & WT & - & NA & 100 & WT & - & BM & 60 \\
\hline 7 & WT & - & PB & NA & WT & - & BM & 85 \\
\hline 8 & WT & - & BM & 98 & WT & - & PB & 52 \\
\hline 9 & WT & - & PB & 95 & WT & - & PB & 80 \\
\hline 10 & WT & - & BM & 89 & WT & - & BM & 96 \\
\hline 11 & WT & - & PB & 99 & WT & - & PB & 99 \\
\hline 12 & WT & - & PB & 80 & WT & - & BM & NA \\
\hline 13 & WT & - & BM & 86 & WT & - & BM & 60 \\
\hline 14 & WT & - & BM & 58 & WT & - & BM & 90 \\
\hline 15 & WT & - & BM & 90 & WT & - & BM & 87 \\
\hline $16^{*}$ & WT & - & BM & 72 & WT $\left(\right.$ ITD $\left.^{+}\right)$ & (45) & $\mathrm{BM}(\mathrm{PB})$ & $13(87)$ \\
\hline 17 & WT & - & BM & NA & WT & - & BM & 11 \\
\hline 18 & WT & - & PB & 78 & WT & - & BM & 56 \\
\hline 19 & WT & - & BM & 90 & WT & - & BM & 64 \\
\hline 20 & WT & - & BM & 90 & WT & - & BM & 74 \\
\hline 21 & WT & - & PB MNC & 90 & D835 ${ }^{+}$ & $\approx 50$ & PB MNC & NA \\
\hline 22 & WT & - & BM & 87 & D835 ${ }^{+}$ & $\approx 50$ & BM & NA \\
\hline 23 & WT & - & PB MNC & 90 & ITD $^{+}$ & 42 & BM & 95 \\
\hline 24 & WT & - & BM & 95 & ITD $^{+}$ & 38 & BM & 95 \\
\hline 25 & $\mathrm{ITD}^{+}$ & 20 & PB MNC & 53 & WT & - & BM & 55 \\
\hline 26 & $\mathrm{ITD}^{+}$ & 6 & BM & 88 & WT & - & BM & 92 \\
\hline 27 & $\mathrm{ITD}^{+}$ & 11 & PB & 80 & WT & - & BM & 82 \\
\hline 28 & $\mathrm{ITD}^{+}$ & 28 & BM & 94 & WT & - & BM & 85 \\
\hline 29 & $\mathrm{ITD}^{+}$ & 44 & BM & 95 & WT & - & BM & 44 \\
\hline 30 & D835+ & $\approx 50$ & BM & 95 & D835 ${ }^{+}$ & $\approx 50$ & BM & 96 \\
\hline 31 & D835 ${ }^{+}$ & $\approx 50$ & BM & 60 & D835 ${ }^{+}$ & $\approx 50$ & BM & 60 \\
\hline 32 & $\mathrm{ITD}^{+}$ & 13 & BM & 55 & ITD $^{+}$ & 16 & BM & 96 \\
\hline 33 & $\mathrm{ITD}^{+}$ & 39 & BM & 51 & ITD $^{+}$ & 39 & BM & 60 \\
\hline 34 & $\mathrm{ITD}^{+}$ & 44 & PB MNC & 77 & $\mathrm{ITD}^{+}$ & 45 & NA & NA \\
\hline 35 & $\mathrm{ITD}^{+}$ & 82 & BM & 97 & ITD $^{+}$ & 84 & BM & 92 \\
\hline 36 & $\mathrm{ITD}^{+}$ & 86 & BM & 86 & ITD $^{+}$ & 83 & PB & 93 \\
\hline 37 & $\mathrm{ITD}^{+}$ & 91 & PB & 70 & ITD $^{+}$ & 91 & BM & NA \\
\hline 38 & $\mathrm{ITD}^{+}$ & 5 & BM & NA & $\mathrm{ITD}^{+}$ & 35 & PB & 97 \\
\hline 39 & $\mathrm{ITD}^{+}$ & 23 & PB MNC & 86 & $\mathrm{ITD}^{+}$ & 88 & BM & 100 \\
\hline 40 & $\mathrm{ITD}^{+}$ & 25 & PB & 79 & ITD $^{+}$ & 50 & PB & 99 \\
\hline 41 & $\mathrm{ITD}^{+}$ & $26+2$ & BM & 90 & $\mathrm{ITD}^{+}$ & $56+14$ & BM & 94 \\
\hline 42 & $\mathrm{ITD}^{+}$ & $28+3+1$ & BM & 80 & ITD $^{+}$ & 41 & BM & 99 \\
\hline 43 & $\mathrm{ITD}^{+}$ & 40 & PB MNC & 88 & ITD $^{+}$ & 69 & PB MNC & NA \\
\hline $44 \dagger$ & $\mathrm{ITD}^{+}$ & 44 & BM & 89 & $\mathrm{ITD}^{+}$ & 60 & PB & NA \\
\hline
\end{tabular}

MNC indicates mononuclear cells; BM, bone marrow; PB, peripheral blood; NA, not available. *Information in parentheses relates to second relapse.

†Different mutations were detected at presentation and relapse. 


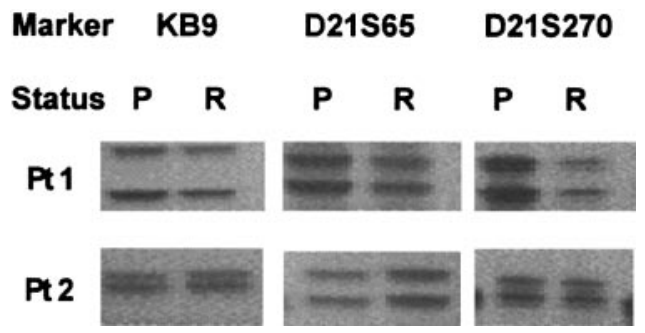

Figure 1. Polymorphic marker analysis in $2 \mathrm{AML}$ patients at presentation $(\mathrm{P})$ and relapse (R). Both patients presented with a FLT3/ITD, which was lost at relapse.

patients with ITDs, the mutant levels were $38 \%$ and $42 \%$, respectively, suggesting that most cells at relapse were heterozygous for the mutant alleles. No ITD was detected in presentation samples from the latter 2 patients using the more sensitive radioactive PCR, and all 4 patients had high blast counts at diagnosis (patients 21-24, Table 2). These results suggested that a FLT3 mutation had not been missed at diagnosis and that its acquisition at relapse was evidence of clonal progression. In 3 of these 4 patients, sufficient DNA was available at both presentation and relapse to study the alleles at 3 loci known to be polymorphic for repeat sequences. In each case they confirmed that the 2 samples came from the same individual. The median time between remission and relapse was similar in the patients who remained WT and those who acquired an FLT3 mutation (367 days; range, 70-1779 days). One patient who had only WT FLT3 alleles at presentation and first relapse acquired an FLT3/ITD at second relapse with a mutant level of $45 \%$. Polymorphic markers indicated that all 3 samples were from the same patient.

Patients with an FLT3 mutation at presentation. Twenty patients were studied who had an FLT3 mutation at presentation: 18 were $\mathrm{ITD}^{+}$with median mutant level $28 \%$ (range, 5\%-91\%), and 2 had D835Y mutations at about the 50\% mutant level (Table 2). The median time to relapse was 218 days (range, 38-716 days), which was less than in those patients who had not had an FLT3 mutation at presentation $(P=.008$, Student $t$ test).

Five patients (25\%) lost their FLT3 mutation at relapse. All had presented with an ITD, and the mutant levels were $6 \%, 11 \%, 20 \%$, $28 \%$, and $44 \%$. Polymorphism analysis demonstrated that the paired samples were from the same individual in 4 cases from whom DNA samples were available (Figure 1); only RNA was available in the remaining patient. The loss was confirmed by radioactive PCR. In 4 of the 5 patients, the percentage of blast cells was similar in the presentation and relapse samples (nos. 25-28, Table 2) and therefore it is unlikely that the mutation had been missed at relapse. In the remaining patient (no. 29), the blast cell count was lower at relapse $(44 \%)$ than at presentation $(95 \%)$. However, at diagnosis all cells appeared to be heterozygous for the mutation (mutant level, 44\%), and therefore, even with the lower blast cell count, a heterozygous mutation would still have been well within the limits of detection of the technique.

Fifteen patients had an FLT3 mutation at both presentation and relapse: 2 had D835Y mutations at both stages of their disease and 13 had ITDs. Sequencing and semiquantitative PCR showed that 6 patients relapsed with the same ITD at approximately the same level (nos. 32-37, Table 2). The median difference between presentation and relapse in the level of mutant was $0 \%$ (range, $-3 \%$ to $+3 \%$ ). Of these patients, 3 had levels of mutant that were consistent with homozygosity or hemizygosity in most blast cells at both presentation and relapse (nos. 35-37). Six patients relapsed with the same ITD but at an increased level, where the median difference between presentation and relapse in the level of mutant was $29.5 \%$ (range, $13.5 \%-45 \%$ ) (nos. 38-43, Table 2). In 1 of these patients, 3 different ITDs were detected at diagnosis (mutant levels $28 \%, 3 \%, 1 \%$, respectively), but only the predominant mutation was present at relapse (no. 42, Table 2). Another patient (no. 41, Table 2) had 2 different ITDs at diagnosis, mutant levels $26 \%$ and $2 \%$, and both were increased at relapse, $56 \%$ and $14 \%$, respectively. The remaining patient who was $\mathrm{ITD}^{+}$at presentation, mutant level $44 \%$, relapsed with a different ITD, mutant level $60 \%$ (\#44, Table 2). The relapse mutation was not detectable in the presentation sample using radioactive PCR analysis. At presentation the ITD was $33 \mathrm{bp}$, nucleotides 36503-36535 from the DNA sequence (Genbank accession no. 13628652), whereas at relapse the ITD was $60 \mathrm{bp}, 51 \mathrm{bp}$ from nucleotides 36481-36531 plus an additional insertion of 9 bp (Figure 2). Polymorphic markers confirmed that the samples were from the same individual.

\section{Analysis of N-Ras mutations in selected patients}

Recent studies indicated that the presence of both a FLT3 and an $\mathrm{N}$-Ras mutation in the same individual is infrequent, ${ }^{18}$ suggesting that both mutations confer a proliferative or survival advantage through a common pathway. We therefore determined $\mathrm{N}$-Ras mutational status at codons 12,13 , and 61 both at presentation and at relapse in those patients whose FLT3 status had changed. Of the 4 patients who acquired a FLT3 mutation at first relapse, none had had an $\mathrm{N}$-Ras mutation at presentation and one acquired an $\mathrm{N}$-Ras codon 61 (position 2, A > G) mutation at relapse, coincident with the development of a D835Y mutation. Of the 5 patients who lost an ITD at relapse, only 1 had acquired an $N$-Ras mutation in codon 12 (position 2, G > A).

\section{Discussion}

In hematologic malignancies with disease-specific markers, the ability to test for MRD using sensitive molecular analyses is now a useful tool for predicting which patients are at risk for relapse. This information is also used in determining therapeutic strategies. For example, after allogeneic transplantation in patients with CML, intervention with donor lymphocyte infusions before the onset of hematologic relapse has been shown to be associated with an increased likelihood of antileukemic response and absence of bone marrow aplasia. ${ }^{28}$ Similarly, in acute promyelocytic leukemia, conversion to PCR positivity for PML/RAR $\alpha$ in 2 successive bone marrow samples after consolidation chemotherapy is being used as a trigger to initiate salvage treatment. ${ }^{16}$ However, the clinical potential for such analysis in AML is restricted by the paucity of suitable markers. The recent identification of activating mutations in the FLT3 gene as the most common mutation in AML, occurring in up to one third of adult patients, ${ }^{18,19,24}$ suggests that the mutations may be a relevant marker for MRD.

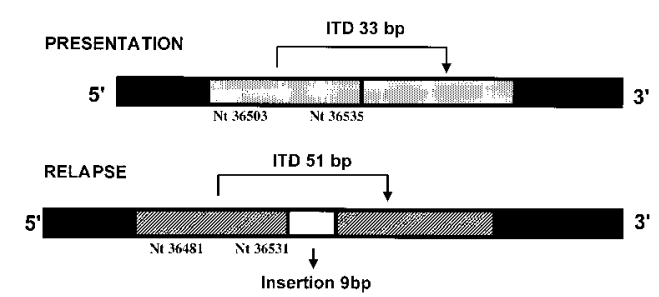

Figure 2. The position of the FLT3/ITDs detected in one patient at presentation and relapse. 
To investigate this we first confirmed that the mutation is found only in leukemic cells. Analysis of a small group of 13 patients in morphologic remission demonstrated that neither the presentation ITDs nor D835 mutation could be detected in bone marrow or peripheral blood samples obtained after induction chemotherapy. Of the patients, 8 had had mutant levels of $40 \%$ to $46 \%$ of total FLT3, indicating that most cells carried the mutation (assuming heterozygosity), and 2 of the patients had had evidence for biallelic mutations or loss of one allele, with mutant levels of $74 \%$ and $90 \%$, respectively.

For a leukemic marker to be clinically useful as an early predictor of relapse, it is important that the marker consistently reappears at relapse. However, 5 (25\%) of the 20 patients who were positive for a FLT3 mutation at diagnosis lost their mutation at relapse. All had had ITDs, and the level of mutant suggests that in 3 of them at least half of the cells in the sample analyzed carried the mutation. This is consistent with a study by Nakano et a ${ }^{29}$ in which 1 of $6 \mathrm{ITD}^{+}$patients at presentation were $F$ LT3/WT at relapse, but differs from Schnittger et al, ${ }^{30}$ who reported that all 25 patients with a mutation at presentation relapsed with the same marker. The inability to detect a mutation at relapse in our study cannot be attributed to insensitivity of the technique used, because in all 5 cases the negative results from the cold PCR used bone marrow samples and were confirmed by the more sensitive radioactive PCR, which can detect ITDs at least at the $0.5 \%$ level. Furthermore, in 4 of the 5 patients the blast cell counts were similar to those at presentation. A number of other complexities arise that are relevant for MRD detection, particularly for ITDs. At diagnosis, 2 patients had evidence of more than 1 mutation, and in 1 of these patients only 1 of the 3 ITDs was detected at relapse. This indicated that the different mutants were present in separate subclones, only 1 of which survived or was selected after chemotherapy. In the other patient both mutants were detected at relapse at increased levels, although in different relative proportions. It is not possible to determine whether the mutants were in separate clones that both survived, or whether the minor mutant was acquired on the other allele in a cell that was already heterozygous for an ITD and neither clone was completely eliminated by the treatment. In addition, 1 patient with an ITD at diagnosis relapsed with a completely different ITD, which would present as a false-negative result if mutation sequence-specific primers were used to improve the sensitivity of the assays used. Analysis of FLT3 mutations as an early indicator of relapse should therefore be used with caution.

The results of this study also shed light on the role of FLT3 mutations in the pathogenesis of AML. The findings show that these mutations may be present in only a minority of blast cells at presentation, and at relapse the ratio of mutant to WT allele frequently increases, as seen in 6 of 12 patients with the same ITD mutation at presentation and relapse (nos. 38-43, Table 2). Results in 3 of these patients were consistent with a greater proportion of ITD $^{+}$blast cells at relapse (nos. 39-41), and in 1 patient (no. 39) relapse appeared to be associated with the development of homozygosity or hemizygosity for the mutant in at least some of the cells. This indicates that the FLT3 alterations can be secondary mutations arising in an already malignant clone, with selection of the subclone containing the FLT3 mutation because of the growth or survival advantage it confers. Five $(21 \%)$ of 24 patients who were WT at presentation acquired FLT3 mutations for the first time in either first or second relapse, which is similar to the frequency found at presentation. ${ }^{18,19}$ This is fully in accord with the fact that FLT3 mutations are secondary events. It also indicates that the FLT3 pathway is active in myeloid cells at the stage of differentiation equivalent to the clonogenic leukemic cell, as the presence of these random mutations occurring in an already transformed clone lead to its further selection. The observation that at relapse 1 of 20 patients had a different mutation and 5 had lost the FLT3 mutation is also compatible with this model. For this to occur, another subclone would need to develop from a leukemic cell that had been present at diagnosis but did not contain the FLT3 mutation. To outgrow the mutant FLT3 ${ }^{+}$cells, this subclone must have acquired alternative mutation(s) imparting a greater survival/growth advantage than that provided by the original FLT3 mutation. One possibility is a secondary mutation in $N$-Ras, as such mutations have been documented to arise in relapse when not present at diagnosis. ${ }^{29,31}$ This is a potential target as FLT3 activates N-Ras, ${ }^{32}$ and the rarity of FLT3 mutations and N-Ras mutations in the same blast cells suggests that both mutations are predominantly using the same pathways. ${ }^{18}$ In the 5 patients we studied who lost FLT3 mutations at relapse, only one acquired an $N$-Ras mutation. Consequently, in the future it may be informative to screen for mutations in other candidate genes.

These results have implications for the therapeutic use of FLT3 kinase inhibitors in patients whose cells express FLT3 mutations. ${ }^{33,34,35}$ As these mutations are secondary events, which is in marked contrast to the BCR/ABL translocation in CML, there will always be a high probability that leukemic subclones not containing the mutant will be present that will have a selection advantage in the presence of a FLT3 kinase inhibitor. Such inhibitors will therefore need to be used in combination with other agents.

\section{Acknowledgment}

The AML DNA and RNA bank is supported by the United Kingdom Medical Research Council and the Leukaemia Research Fund.

\section{References}

1. Grimwade D, Walker H, Oliver F, et al. The importance of diagnostic cytogenetics on outcome in AML: analysis of 1,612 patients entered into the MRC AML 10 trial. The Medical Research Counci Adult and Children's Leukaemia Working Parties. Blood. 1998;92:2322-2333.

2. Goulden N, Oakhill A, Steward C. Practical application of minimal residual disease assessment in childhood acute lymphoblastic leukaemia. $\mathrm{Br} \mathrm{J}$ Haematol. 2001;112:275-281.

3. Beishuizen A, Verhoeven MA, van Wering ER, Hahlen K, Hooijkaas H, van Dongen JJ. Analysis of $\mathrm{Ig}$ and T-cell receptor genes in 40 childhood acute lymphoblastic leukemias at diagnosis and subsequent relapse: implications for the detection of minimal residual disease by polymerase chain reaction analysis. Blood. 1994; 83:2238-2247.

4. Cave H, van der Werff ten Bosch J, Suciu S, et al. Clinical significance of minimal residual disease in childhood acute lymphoblastic leukemia. European Organization for Research and Treatment of Cancer-Childhood Leukemia Cooperative Group. N Engl J Med. 1998;339:591-598.

5. Serrano J, Roman J, Sanchez J, et al. Molecular analysis of lineage-specific chimerism and minimal residual disease by RT-PCR of $\mathrm{p} 210$ (BCR$A B L)$ and $p 190(B C R-A B L)$ after allogeneic bone marrow transplantation for chronic myeloid leukemia: increasing mixed myeloid chimerism and
p190(BCR-ABL) detection precede cytogenetic relapse. Blood. 2000;95:2659-2665.

6. Hochhaus A, Weisser A, La Rosee P, et al. Detection and quantification of residual disease in chronic myelogenous leukemia. Leukemia. 2000; 14:998-1005.

7. Hochhaus A, Reiter A, Saussele S, et al. Molecular heterogeneity in complete cytogenetic responders after interferon-alpha therapy for chronic myelogenous leukemia: low levels of minimal residual disease are associated with continuing remission. German CML Study Group and the UK MRC CML Study Group. Blood. 2000;95:62-66.

8. Olavarria E, Kanfer E, Szydlo R, et al. Early detection of BCR-ABL transcripts by quantitative 
reverse transcriptase-polymerase chain reaction predicts outcome after allogeneic stem cell transplantation for chronic myeloid leukemia. Blood. 2001;97:1560-1565.

9. Yee K, Anglin P, Keating A. Molecular approaches to the detection and monitoring of chronic myeloid leukemia: theory and practice. Blood Rev. 1999;13:105-126.

10. Lo Coco F, Diverio D, Falini B, Biondi A, Nervi C, Pelicci PG. Genetic diagnosis and molecular monitoring in the management of acute promyelocytic leukemia. Blood. 1999;94:12-22.

11. Tobal K, Yin JA. Monitoring of minimal residual disease by quantitative reverse transcriptasepolymerase chain reaction for AML1-MTG8 transcripts in AML-M2 with $\mathrm{t}(8 ; 21)$. Blood. 1996;88: 3704-3709.

12. Marcucci G, Caligiuri MA, Dohner $\mathrm{H}$, et al. Quantification of CBFbeta/MYH11 fusion transcript by real time RT-PCR in patients with INV(16) acute myeloid leukemia. Leukemia. 2001;15:10721080.

13. Laczika K, Novak M, Hilgarth B, et al. Competitive CBFbeta/MYH11 reverse-transcriptase polymerase chain reaction for quantitative assessment of minimal residual disease during postremission therapy in acute myeloid leukemia with inversion(16): a pilot study. J Clin Oncol. 1998;16: 1519-1525.

14. Nucifora G, Larson RA, Rowley JD. Persistence of the 8:21 translocation in patients with acute myeloid leukemia type M2 in long-term remission. Blood. 1993;82:712-715.

15. Miyamoto T, Nagafuji K, Akashi K, et al. Persistence of multipotent progenitors expressing AML1/ETO transcripts in long-term remission patients with $\mathrm{t}(8 ; 21)$ acute myelogenous leukemia. Blood. 1996;87:4789-4796.

16. Diverio D, Rossi V, Avvisati G, et al. Early detection of relapse by prospective reverse transcriptase-polymerase chain reaction analysis of the PML/RARalpha fusion gene in patients with acute promyelocytic leukemia enrolled in the GIMEMAAIEOP multicenter "AIDA" trial. GIMEMA-AIEOP Multicenter "AIDA" trial. Blood. 1998;92:784-789.
17. Tobal K, Newton J, Macheta M, et al. Molecular quantitation of minimal residual disease in acute myeloid leukemia with $t(8 ; 21)$ can identify patients in durable remission and predict clinical relapse. Blood. 2000;95:815-819.

18. Kiyoi $H$, Naoe $T$, Nakano $Y$, et al. Prognostic implication of FLT3 and N-RAS gene mutations in acute myeloid leukemia. Blood. 1999;93:3074 3080.

19. Kottaridis PD, Gale RE, Frew ME, et al. The presence of a FLT3 internal tandem duplication in patients with acute myeloid leukemia (AML) adds important prognostic information to cytogenetic risk group and response to the first cycle of chemotherapy: analysis of 854 patients from the United Kingdom Medical Research Council AML 10 and 12 trials. Blood. 2001;98:1752-1759.

20. Abu-Duhier FM, Goodeve AC, Wilson GA, Care RS, Peake IR, Reilly JT. Genomic structure of human FLT3: implications for mutational analysis. Br J Haematol. 2001;113:1076-1077.

21. Kiyoi H, Towatari M, Yokota S, et al. Internal tandem duplication of the FLT3 gene is a novel modality of elongation mutation which causes constitutive activation of the product. Leukemia. 1998; 12:1333-1337.

22. Fenski R, Flesch K, Serve S, et al. Constitutive activation of FLT3 in acute myeloid leukaemia and its consequences for growth of 32D cells. Br J Haematol. 2000;108:322-330.

23. Hayakawa F, Towatari M, Kiyoi H, et al. Tandemduplicated Flt3 constitutively activates STAT5 and MAP kinase and introduces autonomous cell growth in IL-3-dependent cell lines. Oncogene. 2000;19:624-631.

24. Yamamoto Y, Kiyoi H, Nakano Y, et al. Activating mutation of D835 within the activation loop of FLT3 in human hematologic malignancies. Blood. 2001:97:2434-2439.

25. Abu-Duhier FM, Goodeve AC, Wilson GA, Care RS, Peake IR, Reilly JT. Identification of novel FLT-3 Asp835 mutations in adult acute myeloid leukaemia. Br J Haematol. 2001;113:983-988.

26. Preudhomme C, Warot-Loze D, Roumier C, et al.
High incidence of biallelic point mutations in the Runt domain of the AML1/PEBP2 alpha B gene in $\mathrm{M} 0$ acute myeloid leukemia and in myeloid malignancies with acquired trisomy 21. Blood. 2000; 96:2862-2869.

27. Horwitz M, Benson KF, Person RE, Aprikyan AG Dale DC. Mutations in ELA2, encoding neutrophil elastase, define a 21-day biological clock in cyclic haematopoiesis. Nat Genet. 1999;23:433-436.

28. van Rhee F, Lin F, Cullis JO, et al. Relapse of chronic myeloid leukemia after allogeneic bone marrow transplant: the case for giving donor leukocyte transfusions before the onset of hematologic relapse. Blood. 1994;83:3377-3383.

29. Nakano Y, Kiyoi H, Miyawaki S, et al. Molecular evolution of acute myeloid leukaemia in relapse: unstable N-ras and FLT3 genes compared with p53 gene. Br J Haematol. 1999;104:659-664.

30. Schnittger S, Schoch C, Kern W, Haferlach T, Hiddemann W. FLT3-LM and MLL-PTD as markers for PCR-based detection of Minimal Residual Disease (MRD) in AML with normal karyotype [abstract]. Blood. 2001;98:581a.

31. Bartram CR, Ludwig WD, Hiddemann W, et al. Acute myeloid leukemia: analysis of ras gene mutations and clonality defined by polymorphic $\mathrm{X}$ linked loci. Leukemia. 1989;3:247-256.

32. Dosil M, Wang S, Lemischka IR. Mitogenic signalling and substrate specificity of the Flk2/Flt3 receptor tyrosine kinase in fibroblasts and interleukin 3-dependent hematopoietic cells. Mol Cell Biol. 1993:13:6572-6585.

33. Zhao M, Kiyoi H, Yamamoto $\mathrm{Y}$, et al. In vivo treatment of mutant FLT3-transformed murine leukemia with a tyrosine kinase inhibitor. Leukemia. 2000;14:374-378.

34. Tse KF, Novelli E, Civin Cl, Bohmer FD, Small D. Inhibition of FLT3-mediated transformation by use of a tyrosine kinase inhibitor. Leukemia. 2001;15: 1001-1010.

35. Levis M, Tse KF, Smith BD, Garrett E, Small D. A FLT3 tyrosine kinase inhibitor is selectively cytotoxic to acute myeloid leukemia blasts harboring FLT3 internal tandem duplication mutations. Blood. 2001;98:885-887. 